\title{
Caracterização do Turismo de Base Comunitária em Polos Turísticos do Estado do Pará
}

\section{Characterization of Community-Based Tourism on Touristic Centers in State of Pará (Brazil)}

\author{
Elcivânia de Oliveira Barreto, Alessandra da Silva Lobato, \\ Pablo Vitor Viana Pereira, Débora Rodrigues de Oliveira Serra
}

\section{RESUMO}

Este trabalho buscou analisar as experiências de turismo de base comunitária localizadas em três polos turísticos do estado do Pará, caracterizando-as no contexto regional. O recorte espacial considera os recursos financeiros advindos do Ministério do Turismo por meio do Edital Público № 001/2008, o qual selecionou projetos desse modelo de turismo no Brasil, tendo como representantes paraenses as iniciativas realizadas nos municípios de Curuçá, no Polo Amazônia Atlântica; Soure, no Polo Marajó, e Santarém no Polo Tapajós. Para tanto, foram realizados levantamentos e análises bibliográficas e documentais sobre o tema, bem como trabalhos de campo com aplicação de entrevistas semiestruturadas com representantes das comunidades envolvidas, dos poderes públicos municipais e de organizações não governamentais. Os resultados obtidos com a análise dos dados apontam que as experiências de turismo de base comunitária nos referidos polos diferenciam-se entre si, mas assemelham-se por apresentarem como principal limite o insuficiente apoio do poder público local e, como possibilidade, o aproveitamento do potencial natural e cultural a partir do interesse por parte de grupos das comunidades.

PALAVRAS-CHAVE: Turismo de Base Comunitária; Polo Marajó; Polo Tapajós; Polo Amazônia.

\section{ABSTRACT}

This work aimed to analyze the experiences in community-based tourism located in three touristic poles in state of Pará delineating them on regional context. The spatial clipping considered the financial support from Ministry of Tourism by Public announcement № 001/2008 which selected projects about this tourism model in Brazil, having as representative of Pará the initiatives taken on the counties Curuçá, in Amazonia Atlantic pole; Soure, in Marajo pole, and Santarem, in Tapajos pole. There for, were realized surveys and bibliographical and documentary analysis and on the field applied interviews with communities' leaders, municipal authorities and non-governmental organizations representations. The analysis of data work indicates that the community-based tourism experiences in Pará are different from each other, however, the resemblances are the localization of communities in conservations areas; the not enough public administration support as a main limit, and the cultural and natural potential use interconnected with community participation as possibility.

KEYWORDS: Community-Based Tourism; Polo Marajó; Polo Tapajós. Polo Amazônia. 


\section{Introdução}

As discussões sobre o turismo de base comunitária - TBC surgiram em decorrência de múltiplos fatores, dentre eles a crise socioambiental contemporânea, que está diretamente relacionada à ideologia desenvolvimentista, a qual associa o desenvolvimento ao crescimento econômico e ao progresso técnico-científico, como apontam Araujo e Gelbcke (2008). A partir de sua expansão global, o turismo é atualmente apontado como uma das maiores atividades econômicas no mundo.

Considerando a importância do TBC como alternativa à referida ideologia desenvolvimentista, o presente artigo tem como objeto de pesquisa as experiências desenvolvidas em três polos turísticos do Pará, tendo como recorte espacial os municípios que receberam recursos financeiros advindos do Ministério do Turismo - MTur por meio do Edital Público № 001/2008, o qual, no Pará, selecionou projetos de TBC em Curuçá, no Polo Amazônia Atlântica; Soure, no Polo Marajó, e Santarém, no Polo Tapajós. Assim o objetivo desta pesquisa foi analisar as experiências de turismo de base comunitária no estado do Pará.

Para tanto, realizamos levantamentos e análises bibliográficas sobre o tema em bibliotecas físicas e virtuais das universidades Federal do Pará, de Brasília, de São Paulo e Federal do Rio de Janeiro, bem como em sites especializados, livros, dissertações de mestrado, artigos científicos, entre outros; análise documental, que permitiu “(...) acrescentar a dimensão do tempo à compreensão do social" (CELLARD, 2008, p.295), tornando o documento uma fonte muito importante para análise, porque "(...) tudo o que é vestígio do passado, tudo o que serve de testemunho, é considerado como documento ou fonte" (Idem, 2008, p.296). Acrescenta-se aos procedimentos metodológicos a realização dos trabalhos de campo, os quais corresponderam a viagens aos municípios de Soure e Santarém, no ano de 2011, e Curuçá, no ano de 2013, utilizando, como instrumento de coleta de dados, roteiros de entrevistas com questões semiestruturadas, as quais se caracterizam por "(...) permitir que as pessoas respondam mais nos seus próprios termos do que as entrevistas padronizadas, mas ainda forneçam uma estrutura maior de comparabilidade do que nas entrevistas focalizadas" (MAY, 2004, p. 148). Tais entrevistas se deram com representantes das comunidades envolvidas nos projetos de TBC, dos órgãos municipais de turismo, e das instituições proponentes dos projetos junto ao MTur, a saber: Associação das Mulheres da Vila do Pesqueiro (Soure), Organização Não Governamental Projeto Saúde e Alegria (Santarém) e Instituto Peabiru (Curuçá).

O artigo está estruturado em duas partes: na primeira apresenta-se uma breve reflexão teórica sobre o conceito de turismo de base comunitária e na segunda apresentam-se as experiências do turismo de base comunitária em nossa área de estudo. 


\section{Turismo de Base Comunitária: alguns apontamentos}

No Brasil, o TBC surge como tema de diálogo científico a partir do I Encontro Nacional de Turismo de Base Local (ENTBL), realizado em São Paulo, no ano 1997. Num segundo momento, acrescentou-se ao debate a participação de movimentos sociais durante o I Seminário Internacional de Turismo Sustentável, realizado em Fortaleza, em 2003 (ZECHENER et al., 2008).

No TBC, buscam-se estratégias de desenvolvimento para comunidades associando as dimensões econômica e social. Comunidades são entendidas nesse trabalho como grupos sociais que residem em pequeno espaço geográfico, estabelecendo relações de identidade, pela integração de pessoas entre si, e delas com o lugar. Desse modo, tanto os habitantes, como o lugar são chamados de comunidades (CORIOLANO, 2009).

O desenvolvimento do turismo em comunidades, segundo Mielke (2009) tem sido importante devido a fatores como as possibilidades de criação e estruturação de novos roteiros e destinos turísticos de pequeno porte, que podem contribuir como uma opção complementar de renda.

As comunidades devem ser as principais beneficiadas com a atividade, ao contrário do que se observa no turismo massificado, visto que ele tem gerado graves problemas sociais, econômicos e ambientais, dentre eles a ociosidade de mão-de-obra local durante a maior parte do ano, elevação de preço, especulação imobiliária, segregação entre habitantes locais e visitantes, violência, prostituição, vulgarização da autenticidade e problemas ambientais.

Para Irving (2009), o TBC:

(...) tende a ser aquele tipo de turismo que, em tese, favorece a coesão e o laço social e o sentido coletivo de vida em sociedade, e que por esta via, promove a qualidade de vida, o sentido de inclusão, a valorização da cultura local e o sentimento de pertencimento. Este tipo de turismo representa, portanto, a interpretação "local" do turismo, frente às projeções de demandas e de cenários do grupo social do destino, tendo como pano de fundo a dinâmica do mundo globalizado, mas não as imposições da globalização (p.113).

A referida autora aponta que uma das premissas fundamentais do TBC é a base endógena da iniciativa. Para ela, se a iniciativa:

(...) não tiver motivação endógena e expressar o desejo dos grupos sociais locais, ela certamente não atenderá às demandas de desenvolvimento local e nem contribuirá para o protagonismo social, condição essencial para este tipo de turismo" (IRVING, 2009, p. 114). 
Além da iniciativa endógena para projetos desta natureza, a participação local deve ocorrer nos processos de planejamento, implementação e avaliação dos mesmos. Tal ação representa um elemento eficaz para a sustentabilidade das iniciativas propostas e para a garantia da conservação do patrimônio.

O turismo comunitário "busca se contrapor ao turismo massificado, requerendo menor densidade de infraestrutura e serviços e busca valorizar uma vinculação situada nos ambientes naturais e na cultura de cada lugar" (BURSZTYN, BARTHOLO; DELAMARO, 2009, p.88). Os autores afirmam, ainda, que o TBC busca "um outro modo de visita e hospitalidade, diferenciado em relação ao turismo massificado, ainda que porventura se dirija a um mesmo destino" (BURSZTYN, BARTHOLO; DELAMARO, 2009, p.88).

Ao criar espaços de encontro, o TBC permite o compartilhamento do cotidiano, do lazer, da religiosidade, dentre outras atividades, permitindo que as relações interpessoais sejam favorecidas. Trata-se, portanto, de uma atividade que pode contribuir com o desenvolvimento, não somente econômico, mas também social, que valorize a cultura local, a autonomia do ser humano.

\section{As Experiências de Turismo de Base Comunitária no Pará}

Com base na regionalização do Pará, oficializada pelo Decreto Estadual № 1066/2008 (PARÁ, 2008), bem como no Programa Nacional de Regionalização do Turismo, do MTur, a então Companhia Paraense de Turismo, atual Secretaria de Estado de Turismo do Pará, visando integrar municípios com características semelhantes e complementares, elaborou a Resolução 001/2009, a qual divide o estado em seis polos turísticos (PARÁ, 2008). Dentre tais polos, três tiveram iniciativas de TBC que receberam recursos no ano de 2008 do Ministério do Turismo através do Edital Público № 001/2008, direcionado ao desenvolvimento de projetos voltados ao fomento de práticas de TBC.

Os polos turísticos onde estão localizadas as iniciativas estudadas neste artigo são áreas que apresentam grande diversidade cultural e natural, sendo apontadas no Plano Ver-o-Pará, como regiões turísticas propícias ao desenvolvimento de práticas de turismo que envolvam a comunidade local, seu modo de vida. Assim, este artigo além de tratar de uma questão especifica nesses polos, que são as iniciativas de TBC desenvolvidas, nos revela a diversidade de um estado formado por regiões com grandes extensões territoriais.

O município de Soure, localizado no Polo Marajó, caracteriza-se por praias constantemente visitadas por turistas. A presença de búfalos na paisagem é comum e eles são também utilizados na gastronomia, seja pelo consumo de sua carne ou do queijo. Aliando tais atrativos à hospitalidade dos moradores, implantou-se uma experiência de TBC numa vila de pescadores na Praia do Pesqueiro. Ressalta-se que em tal iniciativa, a comunidade tem consciência de que o turismo é uma atividade 
complementar e que, portanto, não precisam mudar seu modo de vida para impressionar os visitantes.

No Polo Tapajós, uma das principais regiões turísticas do Pará, os atrativos são principalmente "as praias, os rios, as trilhas e as comunidades tradicionais, além de outros inúmeros locais propícios para a prática de atividades de aventura" (PARÁ, 2011, p.77). Tais atrativos concentram-se principalmente em Unidades de Conservação - UCS. As experiências de TBC desenvolvidas nesse polo têm se destacado nos municípios de Belterra e Santarém. Contudo, enfatizaremos a iniciativa realizada em comunidades ribeirinhas de Santarém desde o ano de 2008, por intermédio da ONG Projeto Saúde e Alegria - PSA.

O Polo Amazônia Atlântica, localizado no nordeste paraense, abrange a faixa do litoral Atlântico do estado, que se caracteriza como uma das maiores e mais estruturadas áreas turística de sol e mar da Amazônia Brasileira (PARÁ, 2008). Além de sua biodiversidade, destaca-se sua diversidade cultural com as suas tradições e manifestações como o carimbó, a marujada e o bumba-meu-boi. Apesar de sua tendência para o desenvolvimento do turismo de sol e praia (praia de mar), há também prática de TBC no município de Curuçá.

Conforme veremos a seguir, as experiências de TBC que são apresentadas neste estudo revelam uma diversidade de experiências que se assemelham por serem realizadas por comunidades que buscam uma possibilidade de desenvolvimento não atrelado apenas ao econômico, mas ao humano, algo fundamental ao se pensar os modelos ideais de desenvolvimento para a Amazônia.

\section{O turismo de base comunitária no polo Marajó: a experiência do projeto Viagem Encontrando Marajó, na Vila do Pesqueiro no município de Soure}

Vila do Pesqueiro é uma comunidade tradicional marajoara, que remete, de acordo com Cruz (1999), à existência do pesqueiro Real, na então Vila de Monforte, a qual originou Soure e Salvaterra (Figura 1). De acordo com Cruz (1999) este local era um estabelecimento dos indígenas e propriedade da Coroa Portuguesa, sendo este descrito pelo naturalista lusobrasileiro Alexandre Rodrigues Ferreira, que fez uma extensa viagem pelo interior da Amazônia, passando pelo Marajó entre os anos de 1783 e 1792. 


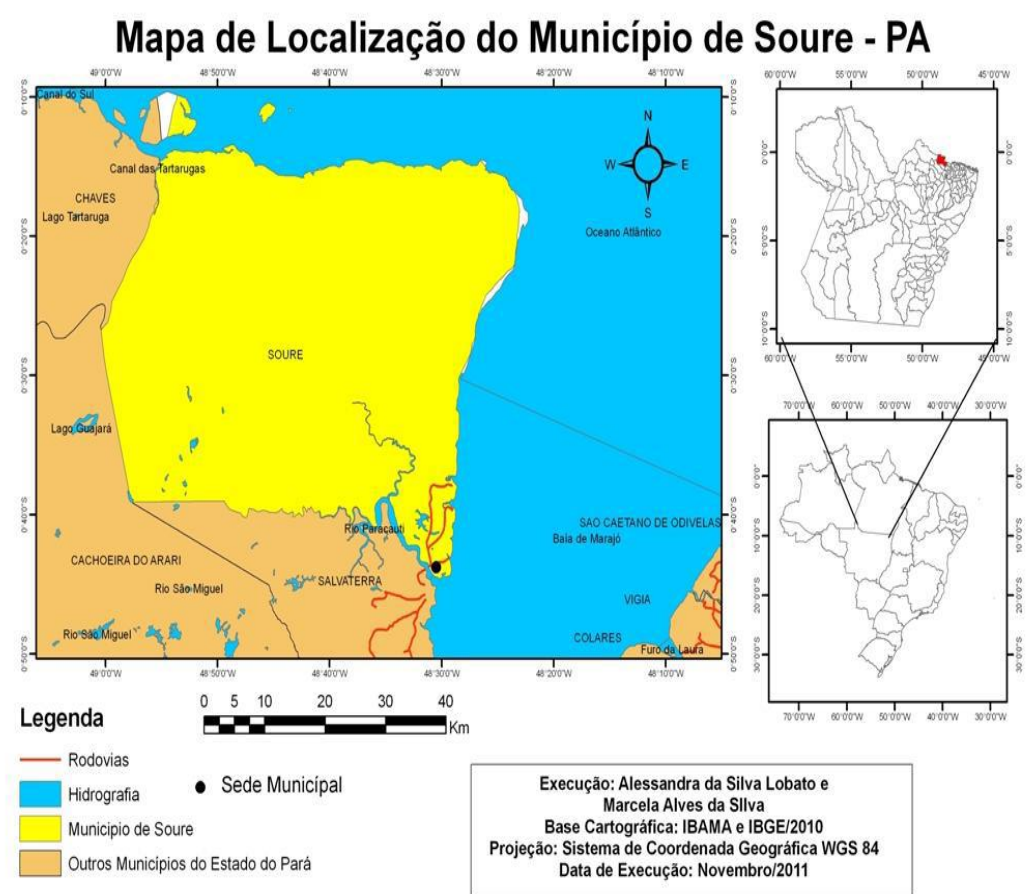

Figura 1: Localização do município de Soure. Fonte: Lobato (2011)

Figure 1: Location of the municipality of Soure (PA, Brazil). Source: Lobato (2011)

A Vila da Praia do Pesqueiro (Figura 2) está situada na Reserva Extrativista Marinha de Soure, distante $8 \mathrm{~km}$ da sede municipal de Soure. Trata-se da primeira reserva extrativista marinha do Pará e em sua área predominam os ecossistemas de manguezais que, junto a igarapés, praias e dunas, compõem um ambiente natural onde é possível realizar diversos passeios. Há ainda a possibilidade de caminhadas noturnas, passeios montados em búfalos ou embarcados em caiaques, nos quais se pode aproveitar o silêncio e a calma para observar a fauna, destacando-se os bandos de guarás e a vegetação típica do mangue. Os passeios também podem ser realizados em charretes puxadas por cavalos ou búfalos, animal de relevante importância, que faz parte da identidade marajoara. Tais atividades são disponibilizadas no Projeto Viagem Encontrando Marajó.

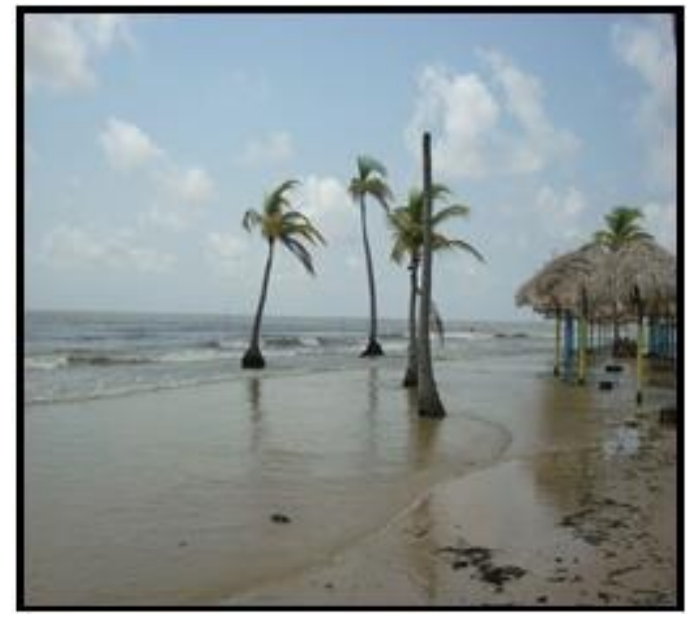

Figura 2: Praia do Pesqueiro. Foto: Lobato, 2010 (trabalho de campo)

Figure 2: Pesqueiro Beach. Photo: Lobato, 2010 (field work) 
A Associação das Mulheres do Pesqueiro foi a proponente do projeto para o Edital № 001/2008 do MTur e é uma organização sem fins lucrativos, que foi fundada em 2002, tendo como objetivo elevar a qualidade de vida e gerar renda para seus associados.

O projeto possui uma estrutura simples, tem a participação direta e indireta de aproximadamente 35 famílias e é formado por 04 frentes de trabalho divididas em equipes responsáveis pela gastronomia, passeios, hospedagem e anfitriões (responsáveis por receber os turistas na sede do município). Há, ainda, o grupo de dança Raízes do Mangue que é formado por crianças com idades entre 06 e 12 anos.

$\mathrm{Na}$ vila existem 07 casas que hospedam, sendo que 05 delas (subdivididas em 02 para hóspedes solteiros e 03 para casais) estão preparadas para que o turista possa ficar em companhia da família. As outras 02 casas estão sem moradores e servem para receber turistas caso a procura seja maior.

O projeto VEM ao proporcionar a ida de turistas à comunidade, também promove a geração de renda para outras pessoas que não participam do projeto, mas que são moradores da Vila, a exemplo do que relatou um dono de restaurante localizados na praia, em entrevista realizada em fevereiro de 2011: "O turista quando vem pra Vila pelo projeto, como ele fica aqui, ele também frequenta os bares daqui, consome as bebidas daqui, isso dá um dinheiro pra nós também".

Nota-se, ainda, que o projeto VEM tem contribuído com a interação entre os comunitários e os turistas, conforme aponta uma participante do projeto, em entrevista realizada em fevereiro de 2011:

\begin{abstract}
Quando as pessoas vem pra cá é um intercâmbio de culturas, eles trazem a cultura deles e conversam sobre como é lá onde moram e o turismo de base comunitária é tudo isso (...) é um intercâmbio cultural imenso o pessoal tá aproveitando bem isso, trocar conhecimento é muito bom, conhecer o outro a sua cultura também.
\end{abstract}

Apesar do empenho da Associação das Mulheres do Pesqueiro para o desenvolvimento dessa atividade, foi possível identificar fatores limitantes ao seu fortalecimento, dentre elas a questão da comunicação interna e externa, considerando que até 2011 os sinais de telefonia móvel eram bem precários. Contudo, um dos principais fatores limitantes apontados pelos envolvidos no projeto, era a falta de parcerias com a prefeitura e outros órgãos municipais e estaduais que pudessem acompanhar e colaborar para a consolidação do TBC.

Os serviços básicos que deveriam ser prestados pelo poder público municipal, como saneamento, rede de abastecimento de água, saúde, poderiam ser melhor estruturados na vila, principalmente, para atender as demandas locais e posteriormente os turistas, como constatou Lobato (2011). 


\section{O turismo de base comunitária no Polo Tapajós: a experiência em comunidades ribeirinhas do município de Santarém}

O Município de Santarém está situado no norte do Brasil, na Mesorregião do Baixo Amazonas, microrregião de Santarém, ocupando uma área aproximada de $22.887 \mathrm{~km}^{2}$, que corresponde a $1,83 \%$ do Pará (BRASIL, 2010). É considerado o centro polarizador da região oeste do estado, uma vez que detém uma alta infraestrutura em relação aos demais municípios, atraindo assim pessoas dos municípios próximos, que buscam serviços. O acesso se dá por meio de transporte aéreo, terrestre, e principalmente fluvial, sendo este último o mais utilizado pela população dos municípios vizinhos (SANTAREM, 2010).

O turismo no município é uma atividade que vem crescendo aos poucos e contribuindo para a sua economia, bem como para o seu desenvolvimento. De acordo com Santarém (2010), o município apresenta vocação para a implementação do turismo ecológico e de aventura, tendo em vista suas belezas naturais como suas praias, cachoeiras, sítios arqueológicos, fauna, flora, lagos, igarapés, além de edificações seculares que realçam sua história. Essa vocação possibilitou sua inserção no programa do Ministério do Turismo dos 65 destinos indutores, além de ter sido eleito Destino Referência em Ecoturismo.

No que refere ao TBC, ele vem sendo desenvolvido em comunidades ribeirinhas sob a coordenação da ONG PSA. Até o ano de 2011, não havia nenhuma ação do órgão municipal de turismo para o fomento do TBC, tampouco voltado para o projeto desenvolvido pela ONG PSA. Segundo Barreto (2015), essa inação do poder público local frente ao TBC até o ano de 2014 ainda prevalecia.

A ONG PSA atua na região oeste do Pará, mais precisamente nas comunidades ribeirinhas do município de Santarém, desde a década de 1980. Sua atuação, inicialmente, se dava apenas em projetos na área da saúde. Ressaltamos que sua experiência de TBC foi selecionada através do edital 001/2008 do Ministério do Turismo para receber recurso para o seu desenvolvimento, envolvendo 04 comunidades ribeirinhas: Anã (localizada na Reserva Extrativista Tapajós Arapiuns), Atodí, Arimum e Vila Amazonas (no Projeto de Assentamento Extrativista Gleba Lago Grande).

A partir de 2009, o projeto de TBC começou a ser implementado nas comunidades iniciando com sua apresentação aos comunitários e com a realização de oficinas de capacitação e da elaboração de inventários turísticos das comunidades.

Nesse sentido, esse projeto se constituiu como uma possibilidade de contribuir para a geração de renda das comunidades envolvidas, além de ampliar e consolidar o programa de TBC por meio de um processo de mobilização, planejamento, organização e qualificação das comunidades, buscando estruturar e fortalecer a estratégia de promoção e comercialização do programa de ecoturismo em articulação com a Rede Brasileira de Turismo Solidário e Comunitário - REDE TURISOL - favorecendo ainda o fortalecimento e a expansão desta rede. Além de se constituir numa 
possibilidade de ampliar a renda, é uma possibilidade de permanência dos jovens nas comunidades.

A partir da organização e capacitação dos comunitários para o desenvolvimento do projeto de TBC, eles começaram a perceber uma possibilidade de desenvolvimento de seu território, bem como valorização de sua cultura, na qual todos os comunitários, mesmo os que não estão envolvidos no projeto, são beneficiados, uma vez que uma parte da renda gerada pelo turismo vai para a associação da comunidade. Além da participação do processo de organização da atividade, os comunitários envolvidos no projeto, em particular os que foram capacitados como condutores, se tornam responsáveis pela capacitação dos que desejam se inserir no projeto.

Os atrativos das comunidades ofertados aos visitantes também corresponderam a um processo de escolha junto com os próprios comunitários, firmando mais uma vez a participação do processo de desenvolvimento do turismo, desde o início da sua implantação. Sendo assim, os turistas ao visitarem as comunidades realizam um roteiro que contém atividades que já faziam parte do cotidiano das comunidades, como pode ser observado no Quadro 1:

\begin{tabular}{|c|c|}
\hline COMUNIDADE & ATIVIDADE \\
\hline ANÄ & $\begin{array}{l}\text { Visita ao projeto de produção de ração } \\
\text { orgânica e criação de peixes em tanque de } \\
\text { rede flutuante do grupo MUSA (Mulheres } \\
\text { Sonhadoras em Ação); Visita ao projeto de } \\
\text { criação de abelhas sem ferrão do grupo } \\
\text { MELIPOMEL; Café, tapioca e roda de } \\
\text { conversa em casas de comunitários; Gincana } \\
\text { cultural; Noite Cultural; Piracaia na praia. }\end{array}$ \\
\hline ATODI & $\begin{array}{l}\text { O processo de fabricação da farinha de } \\
\text { mandioca, a chamada "Farinhada"; trilha dos } \\
\text { castanheiros para em seguida tomar banho } \\
\text { em refrescantes igarapés da comunidade; } \\
\text { refeições que tem o peixe a galinha caipira } \\
\text { como principal produto. }\end{array}$ \\
\hline ARIMÚN & $\begin{array}{l}\text { Banho em rios e igarapés; trilha na mata } \\
\text { conhecendo os inúmeros remédios naturais } \\
\text { ou plantas medicinais utilizados pela } \\
\text { população local, o passeio de canoa em } \\
\text { igarapés e lago, acompanhando os } \\
\text { comunitários nas atividades de pesca; oficinas } \\
\text { de artesanato, neste último a mulheres } \\
\text { artesãs mostram como extrair a palha do } \\
\text { tucumã, e depois mostram aos visitantes e os } \\
\text { envolvem na confecção dos produtos. }\end{array}$ \\
\hline VILA AMAZONAS & $\begin{array}{l}\text { Caminhadas pela mata e pela extensa área } \\
\text { da comunidade, dependendo da época do ano } \\
\text { podem passear de canoas nos lagos da } \\
\text { várzea, participação em pescarias; oficinas de } \\
\text { artesanato; almoço típico a base de peixe e } \\
\text { produtos da terra e da mata. }\end{array}$ \\
\hline
\end{tabular}

Quadro 1: Atividades realizadas pelos visitantes nas Comunidades Ribeirinhas inseridas no projeto de TBC coordenado pela ONG Saúde \& Alegria no município de Santarém-Pará.

Table 1: Activities carried out by visitors in the Ribeirinha Communities inserted in the TBC project coordinated by the NGO Saúde \& Alegria in the municipality of Santarém/PA (Brazil).

Fonte: Barreto (2013).

Source: Barreto (2013) 
Diante do exposto, observamos que o turismo desenvolvido pela ONG diferencia-se do convencional, pois nele se propõe um momento de encontro, entre o visitado (comunidade) e o visitante (turista) havendo respeito mútuo pelas diferenças, privilegiando-se a inserção da comunidade desde o planejamento até a execução da atividade.

Há ainda que considerarmos a inação do Estado, no que se refere principalmente ao poder público municipal e estadual, pela ausência de ações específicas direcionadas a esta prática. Em entrevistas realizadas no ano de 2011 com o então secretário de turismo do município de Santarém, identificamos que este órgão considerava a ONG PSA muito independente e eficiente em suas ações frente às comunidades em que atuavam, entendendo que a atuação da Secretaria, devido a essa presença da ONG, não era tão necessária junto a tais comunidades.

\section{O Turismo de Base Comunitária no Polo Amazônia Atlântica: A experiência do município de Curuçá}

O município de Curuçá está localizado na região nordeste do estado do Pará (Figura 3) e nele está inserida a Reserva Extrativista Mãe Grande de Curuçá, de instância federal. Na região existem, ainda, duas unidades de conservação em municípios próximos: a Área de Proteção Ambiental (APA) de Algodoal e a Reserva Extrativista (Resex) de Maracanã.

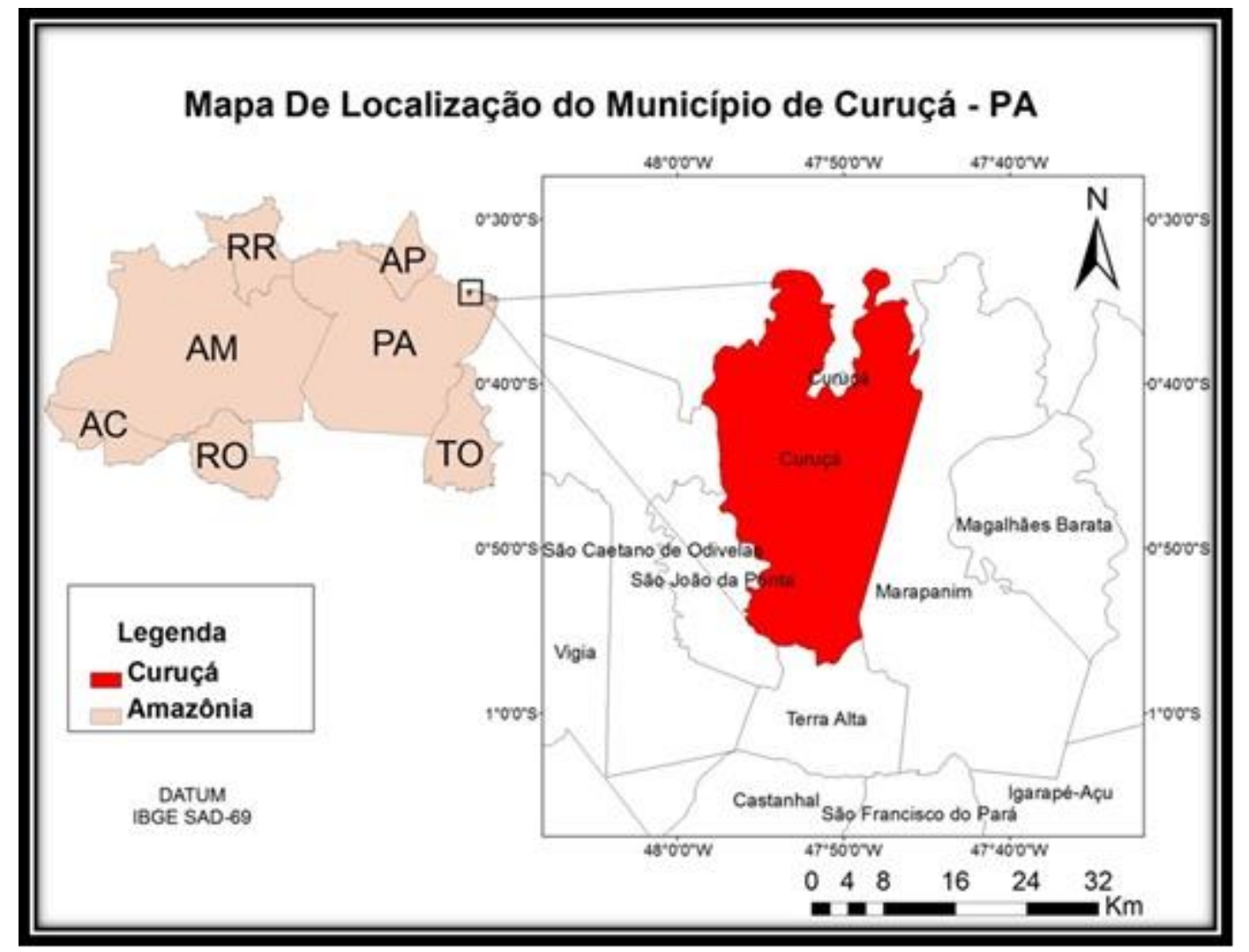

Figura 3: Localização de Curuçá (PA).

Figure 3: Location of Curuçá (PA).

Fonte: Pereira (2013).

Source: Pereira (2013). 
Curuçá (PA) possui um dos maiores manguezais do planeta, apresentando uma rica biodiversidade, onde as comunidades desenvolvem atividades extrativistas como a pesca. O turismo surge como uma alternativa sustentável para conservação dos patrimônios cultural e ambiental. Nessa perspectiva que foi criado o Projeto de TBC que teve como proponente para o Edital № 001/2008 do MTur o Instituto Peabiru, com a missão de "gerar valores para a conservação da biosociodiversidade da Amazônia"1, no qual fundou o Museu do Mangue e desenvolveu projetos de turismo, biojóias e criação de abelhas nativas, gerando emprego para população local.

Com as ações do Programa Casa da Virada, desenvolvido pelo Instituto Peabiru, foi criado pelos filhos e filhas de pescadores, agricultores e professores, o Instituto Tapiaim (Figura 4), uma instituição sem fins lucrativos destinada a receber turistas em Curuçá para realizar práticas de ecoturismo de base comunitária ${ }^{2}$. Todavia, apesar da organização da comunidade com a criação desse instituto, houve pouco avanço na estruturação do TBC em Curuçá, visto que as ações voltadas ao seu planejamento não foram concretizadas, dificultando a continuidade de suas atividades. Conforme entrevista concedida pelo presidente do Instituto Tapiaim, em setembro de 2013, apesar de exercer um importante papel junto à comunidade, o referido instituto encontra-se inativo porque a maioria dos seus membros reside atualmente em outras cidades, enquanto os demais estão estudando e trabalhando, não dispondo de tempo para dedicar às atividades planejadas.

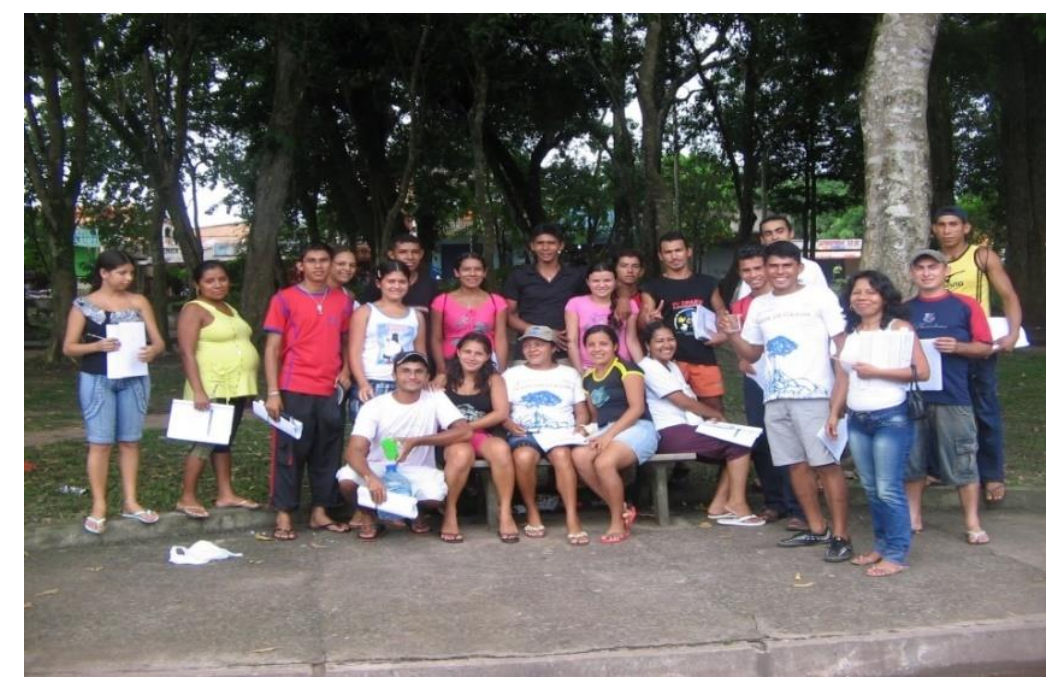

Figura 4: Reunião com os integrantes do Instituto Tapiaim, Curuçá (PA). Figure 4: Meeting with the members of the Tapiaim Institute, Curuçá (PA).

Fonte: Blog do Instituto Tapiaim ${ }^{3}$.

Source: Tapiaim Institute Blog ${ }^{3}$.

Vale mencionar que atualmente está sendo desenvolvido outro projeto de turismo de base comunitária na cidade de Curuçá, pelo instituto Lá no Mangue $^{4}$, iniciativa realizada por moradores. Este novo instituto tem objetivos de conservação e desenvolvimento equitativo, além de valorizar a diversidade social e ambiental. Conforme Pereira (2013), as ações vêm sendo desenvolvidas, no entanto, de forma esporádica. 


\section{Considerações finais}

O Turismo de Base Comunitária, compreendido como uma possibilidade de gestão da atividade turística com a participação da comunidade local, é um movimento que em seus princípios se contrapõe ao turismo convencional, pois permite uma maior aproximação com a cultura, com o modo de vida das populações que são visitadas, mas que também promove um intercâmbio cultural, possibilitando trocas das experiências vividas entre visitante e visitado, e o compartilhamentos dos espaços utilizados pela comunidade com o visitante. Retomando as ideias de Irving (2009, p.113), ratificamos que o TBC deve "(...) favorecer a coesão e o laço social e o sentido coletivo de vida" e somente com a participação da população local no processo de planejamento, execução e monitoramento da atividade, isso se tornará possível. É sob este olhar que as nossas análises em torno das experiências de TBC nos polos turísticos do estado do Pará se assentam.

Considerando neste estudo as experiências de TBC nos polos turísticos do Marajó, Tapajós e Amazônia Atlântica, identificamos que o recurso advindo do Ministério de Turismo, no ano de 2008, foi empregado principalmente na estruturação de roteiros turísticos e na capacitação de comunitários que atuariam diretamente com o projeto. Vale mencionar que foi a primeira vez que o órgão oficial de turismo em nível federal direcionou recursos para o fomento dessa prática. Em nível estadual e municipal tais ações foram pontuais, não se configurando como ações efetivas, assim como não foram direcionadas para as experiências analisadas.

Além disso, a análise dos dados obtidos em trabalho de campo, revelaram que as experiências de TBC desenvolvidas nos Polos Marajó e Tapajós, respectivamente nos municípios de Soure e Santarém, se apresentam como uma realidade, e tem buscado vislumbrar os princípios elencados por Irving, buscando realçar o modo de vida da população visitada como o principal atrativo, e estabelecer de fato um momento de encontro entre comunitário e visitante. Realidade esta, que não identificamos no Polo Amazônia Atlântica, especificamente no município de Curuçá.

Tanto no município de Soure, na Vila do Pesqueiro, quanto no município de Santarém, as experiências de TBC são desenvolvidas em parceira com as ONGs Associação das Mulheres do Pesqueiro e Projeto Saúde e Alegria, respectivamente, sendo elas proponentes e o executoras do projeto junto às comunidades. Diferente da realidade de Curuçá, onde a pesquisa apontou que o Instituto Tapiaim, apesar de ter exercido um importante papel como facilitador nas ações de planejamento, não houve fortalecimento entre os membros no que tange aos objetivos coletivos.

Pode se considerar a princípio, que a experiência de TBC coordenada pela ONG PSA vem envolvendo a comunidade ou pelo menos parte desta no processo de planejamento e gestão do turismo, o que em certa medida torna-os protagonistas no processo, constituindo-se com uma grande possibilidade de desenvolvimento local, que inclui dentre outros elementos uma alternativa a mais de geração de renda, resgate da memória e valorização do modo de vida, possibilitando a permanência dessas 
comunidades em seu território, que para além do valor econômico detém um valor simbólico.

Tal experiência revela que o planejamento e execução da atividade se centralizam nos comunitários e em parte na ONG PSA, esta que, de certa forma, assume o papel do poder público. Apesar da presença da ONG na coordenação do Projeto de TBC, a proposta é na verdade incitar nos comunitários a autonomia diante da atividade em suas comunidades, levando adiante o projeto, independente de ONGs ou de empresas privadas.

Diante disso, compreendemos que as experiências de TBC apresentadas neste artigo, até o ano de 2011(Polo Marajó e Tapajós) e 2013 (Polo Amazônia-Atlântica), período em que foram realizados os trabalhos de campo, correspondiam a uma possibilidade de desenvolvimento local e inclusão social das comunidades tradicionais de ambos os municípios estudados, uma vez que estas inserem as comunidades como sujeitos atuantes, desde a elaboração, planejamento e execução da atividade em seus territórios, instigando, nos comunitários, a sua autonomia no processo, além de incitar o desenvolvimento de seu território, que inclui a melhoria da qualidade de vida da população local, além da conservação de seus patrimônios naturais e culturais, e, ainda, firmando a sua identidade enquanto populações tradicionais. São elementos que podemos apontar como fortes em nossa pesquisa, além do interesse dos comunitários em participar do projeto.

Contudo, não se pode prescindir do papel poder público local neste processo, o qual até o ano da pesquisa mantinha-se alheio tanto frente aos projetos de TBC desenvolvidos no Marajó, Tapajós e Amazônia-Atlântica, o que, pode ser apontado como um dos principais fatores limitantes ao desenvolvimento e consolidação do TBC nas comunidades estudadas. Assim como as organizações não governamentais e as populações são agentes importantes, é necessária a atuação do poder público, principalmente em nível municipal, na elaboração de políticas, programas e ações, os quais serão fundamentais para o fortalecimento das comunidades em seus territórios, bem como para a consolidação do TBC como possibilidade de desenvolvimento territorial.

Finalmente, compreendemos que é necessário avançar no que tange à autogestão dos projetos de TBC na região Amazônica e fortalecer a cooperação que permita o envolvimento do governo em conjunto com a comunidade e o mercado.

\section{Referências}

ARAUJO, G. P. de; GELBCKE, D. L.. Turismo Comunitário uma perspectiva ética e educativa de desenvolvimento. Revista Turismo Visão e Ação Eletrônica, v. 10, no 03. p. 357 - 378, set/dez. 2008. Disponível em: www.univali.br/revistaturismo. Acessado em: 01/08/2010. 
BARRETO E.B. O Turismo de Base Comunitária e a Inclusão Social de Comunidades Tradicionais Ribeirinhas da Amazônia: Um Estudo da Experiência de TBC no Município De Santarém/Pará. Anais do Encontro Nacional da Associação Nacional de Pós-Graduação e Pesquisa em Geografia, 2013, Campinas, São Paulo. Anais do ENANPEGE, 2013.

BARRETO E.B. Turismo de Base Comunitária e uso do Território em Comunidade Ribeirinha da Amazônia Paraense: $O$ Caso de Anã no Município de Santarém/Pará. Dissertação (Mestrado em Geografia). Instituto de Filosofia e Ciências Humanas, Universidade Federal do Pará, Belém/PA, 2015.

BRASIL. Censo Demográfico 2010. Instituto Brasileiro de Geografia e Estatística IBGE. Disponível em:

$<$ http://www.cidades.ibge.gov.br/xtras/perfil.php?lang=\&codmun=150680 >. Acesso em: Jun 2016.

BURSZTYN, I.; BARTHOLO, R.; DELAMARO, M. Turismo para quem? Sobre caminhos de desenvolvimento e alternativas para o turismo no Brasil. In: BARTHOLO, R.; SANSOLO, D.G.; BURSZTYN, I. (Org.). Turismo de Base Comunitária: diversidade de olhares e experiências brasileiras.1. ed. Rio de Janeiro: Ed. Letra e Imagem, 2009.

CELLARD, A. A análise documental. In: Poupart et al. (Org.). A pesquisa qualitativa: enfoques epistemológicos e metodológicos. Tradução de Ana C. N. Petrópolis: Vozes, 2008. p. 295-316.

CORIOLANO, L.N.M.T. et al. Arranjos produtivos locais do turismo comunitário: atores e cenários em mudança. Fortaleza: Ed. UECE, 2009.

CRUZ, M.E.M.da. Soure pérola do arquipélago do Marajó. Belém: Empresa Jornalística e Editora Gráfica M. M. Lima Ltda., 1999.

IRVING, M. Reinventando a reflexão sobre turismo de base comunitária. In: (Org.) BARTHOLO, R; BURSZTYN, I; SANSOLO, D. Turismo de Base Comunitária: diversidade de olhares e experiências brasileiras. Rio de Janeiro: Ed. Letra e Imagem, 2009.

LOBATO, A.S. Turismo de base comunitária e desenvolvimento socioespacial na vila do Pesqueiro, município de Soure (Ilha do Marajó-PA). Trabalho de Conclusão de Curso - Departamento de Geografia, IFCH, UFPA, Belém, 2011.

MAY, T. Entrevistas: métodos e processos. In: MAY, T. Pesquisa Social: questões, métodos e processos. Trad. Carlos A. S. N. S. 3 ed. Porto Alegre: Artmed, 2004.

MIELKE, E. J. C. Desenvolvimento Turístico de Base Comunitária. Campinas, São Paulo:Átomo \& Alínea, 2009, v.1, 2009.

PARÁ. Decreto № 1.066, de 19 de junho de 2008. Disponível em: $<$ http://www.ioepa.com.br>. Acesso em: 30 jul 2016.

PARÁ. Resolução № 001/2009. Disponível em: <http://www.ioepa.com.br>. Acesso em: 30 jul 2016.

PARÁ. Ver-o-Pará: Plano Estratégico de Turismo do Estado do Pará. Belém: Companhia Paraense de Turismo, 2011.

PEREIRA, P.V.V. Arranjo socioprodutivo de base comunitária e capital social: contribuições para uma proposta de agência de turismo comunitária em Curuçá Pará. Trabalho de Conclusão de Curso - Faculdade de Turismo, ICSA, UFPA, Belém, 2013. 
SANTARÉM. Informações Municipais de Santarém. Secretaria Municipal de Planejamento e Coodenação Geral - SEMPLAN; Centro Municipal de informações Ambientais - CIAM. Belém 2010.

ZECHENER, T.C.; HERIQUEZ, C.; SAMPAIO, C.A.C. Pensando o conceito de turismo comunitário a partir de experiências brasileiras, chilenas e costarriquenha. Anais do II Seminário Internacional de Turismo Sustentável, Fortaleza-CE, maio/2008.

\section{Notas:}

${ }_{1}^{1}$ Disponível em: <http://casadavirada.blogspot.com.br/2009/05/comercializacao-de-mel-viraalternativa.html>. Acesso em: 03 ago. 2016

2 Disponível em: < http://institutotapiaim.blogspot.com.br/>. Acesso em: 03 ago. 2016.

3 Disponível em: <http://www.institutotapiaim.blogspot.com.br/p/curuca.html>.Acesso em: 15 mar. 2013

${ }^{4}$ Disponível em: <http://www.institutobrasiljusto.org.br/Amazonia justa.html> Acesso em: 17 ago. 2016.

Elcivânia de Oliveira Barreto: Secretaria Municipal de Desenvolvimento e Turismo de Santarém, Santarém, PA, Brasil.

E-mail: vaniabarreto21@gmail.com

Link para o currículo Lattes: http://lattes.cnpq.br/2580025480478892

Alessandra da Silva Lobato: Universidade Federal do Pará, Belém, PA, Brasil.

E-mail: alessandrageo19@yahoo.com.br

Link para o currículo Lattes: http://lattes.cnpq.br/8962068868240430

Pablo Vitor Viana Pereira: Universidade Federal do Pará, Belém, PA, Brasil.

E-mail: pablo.viana28@gmail.com

Link para o currículo Lattes: http://lattes.cnpq.br/1550483432633898

Débora Rodrigues de Oliveira Serra: Secretaria de Estado de Turismo do Pará, Belém. PA. Brasil

E-mail: debserra1980@hotmail.com

Link para o currículo Lattes: http://lattes.cnpq.br/1173440775476563

Data de submissão: 9 de novembro de 2016

Data de recebimento de correções: 3 de fevereiro de 2017

Data do aceite: 17 de fevereiro de 2017

Avaliado anonimamente 